\title{
Development of the Cell Transmission Model for Traffic Signal Coordination
}

\author{
Lye Yoke Kei $^{1)} \&$ Susilawati $^{1, \text { a) }}$ \\ ${ }^{1)}$ Civil Engineering Dept., Monash University Malaysia, Bandar Sunway, Malaysia. \\ Correspondent : ${ }^{a}$ susilawati@monash.edu
}

\begin{abstract}
This research aims to develop a macroscopic traffic model to estimate delay at signalized intersections by considering queue forming and dissipation in the presence of a pre-timed signal. Cell Transmission Model (CTM) was set up with basic traffic input parameters to estimate delay and level of service (LOS) and the results are compared to a computational analysis run by SIDRA (Signalized and Unsignalized Intersection Design and Research Aid) software. To optimize the traffic flow condition, traffic signal coordination is carried. It was found that the optimized traffic signal setting reduces delay by $25.5 \%$ and $17 \%$ in Intersection A and Intersection B after a second run by CTM.
\end{abstract}

Keywords : infrastructure management, road network operation, cell transmission model, delay, traffic signal coordination.

\section{INTRODUCTION}

The urban road network is vital for the wellbeing of the city. These infrastructures must be well managed, in terms of development, operation, and maintenance (Suprayitno \& Soemitro, 2018). Signalized intersections are one of the important components for the urban road network operation. The knowledge of this operation needs to well understood, well implemented and well developed.

In an urban transportation network, vehicles often experience queuing and delay at signalized intersections. As vehicles are obliged to idle and queue at intersections with a fixed signal setting, there is a high likelihood of traffic congestion incurred when the traffic demand peaks. While the implementation of the traffic signal aims to maintain smooth traffic flow across the intersection, it should not disrupt the traffic flow to the extent of excessive delay if it is timed inappropriately. Hence it is important to develop a predictive traffic model that helps researchers to understand the phenomenon of queue formation, propagation, and dissipation at signalized intersections. The signal timing optimization is then implemented to reduce the average delay experienced by the vehicles.

The research objectives are :

1. To develop a predictive macroscopic model in simulating queue formation and dissipation at a signalized intersection.

2. To validate the accuracy of the Cell Transmission Model (CTM) in comparison with SIDRA software for delay estimation.

3. To investigate the effectiveness of traffic signal setting coordination in reducing traffic congestion.

The research is conducted expecting that CTM is able to predict queue formation and dissipation and hence delay at a signalized intersection. Delay output from CTM is compared to the delay from SIDRA analysis with the expectation that both yield similar results given the 
same traffic condition. The improved traffic signal setting is also expected to reduce traffic delay at a signalized intersection.

The scope of this research focuses on modeling traffic flow on two-way urban arterials with three-legged signalized intersections. The lane configuration is limited to two lanes with a fixed signal setting. As this research focuses on macroscopic level analysis, microscopic characteristics such as driver's lane-changing behavior and degree of aggressiveness are excluded in this research.

\section{LITERATURE REVIEW}

\section{Delay and Level of Service (LOS)}

According to Highway Capacity Manual (2010), the delay is defined as "the additional time experienced by a driver, passenger, or pedestrian". Control delay is the principal service measure for evaluating signalized intersections. It involves the stop-and-go movements at intersection approaches due to the presence of traffic signals and conflicting traffic. The illustration of control delay for a single-vehicle traveling through a signalized intersection is shown in Figure 1.

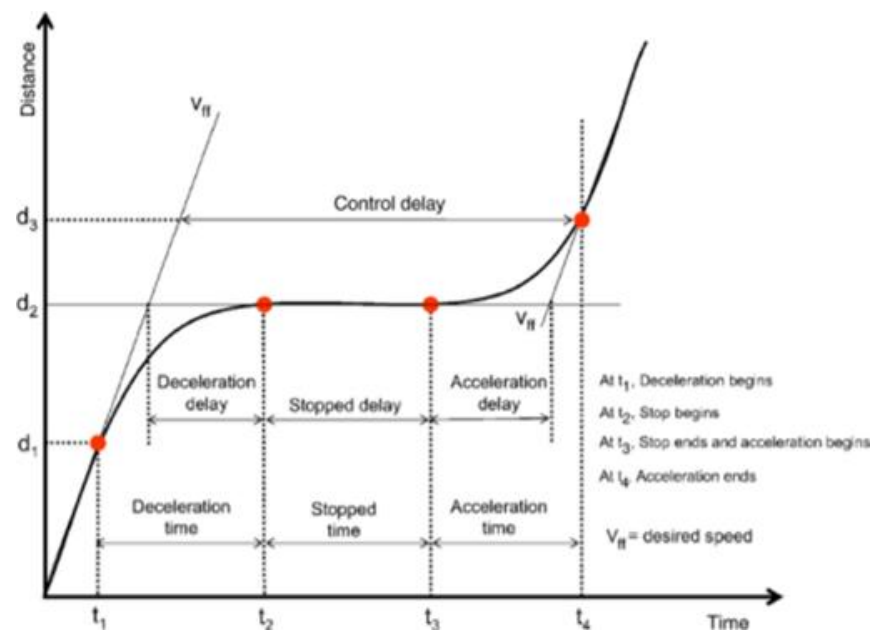

Figure 1. Illustration of control delay for a single-vehicle traveling through a signalized intersection (Wang, J et al. 2008)

When the downstream traffic signal is red, a vehicle traveling from upstream intersection decelerates to a complete halt, waits for the signal to turn green before gradually accelerating back to its free-flow speed. The time taken by the vehicle to undergo this entire process contributes to the control delay. The extent of control delay is a complex measure based on several variables such as traffic volume, signal cycle length, and signal phasing design at the intersection.

Level of service (LOS) is defined in terms of average total vehicle delay of all movements through a signalized intersection. Different LOS threshold values represent the operational conditions within a traffic stream in terms of traffic flow characteristics. The higher the average control delay, the lower the LOS grade which reflects the lower performance of the intersection as there will be less freedom to maneuver, lower level of comfort and convenience, and prolonged queue time. Table 1 shows the LOS criteria for signalized intersections. 
Table 1. Level of Service Criteria for Signalized Intersections (Highway Capacity Manual 2000)

\begin{tabular}{ccc}
\hline $\begin{array}{c}\text { Level } \\
\text { of } \\
\text { Service }\end{array}$ & $\begin{array}{c}\text { Average Control } \\
\text { Delay } \\
\text { (seconds/vehicle) }\end{array}$ & General description \\
\hline $\mathrm{A}$ & $\leq 10$ & Free flow \\
\hline $\mathrm{B}$ & $>10-20$ & Stable flow (slight delays) \\
\hline $\mathrm{C}$ & $>20-35$ & Stable flow (acceptable delays) \\
\hline $\mathrm{D}$ & $>35-55$ & $\begin{array}{c}\text { Approaching unstable flow (tolerable delay, occasionally wait } \\
\text { through more than one signal cycle before proceeding) }\end{array}$ \\
\hline $\mathrm{E}$ & $>55-80$ & Unstable flow (intolerable delay) \\
\hline $\mathrm{F}$ & $>80$ & Forced flow (congested and queues fail to clear) \\
\hline
\end{tabular}

\section{Traffic Signal Control and Optimization}

There are three types of traffic signal control: pre-timed, actuated, and coordinated signal setting. Pre-timed signal control uses fixed cycle time intervals of green, yellow, and red time regardless of the change in traffic demand. It is suitable for intersections with constant traffic volume, however unable to adapt to a sudden increase in traffic volume. An actuated signal control is able to change the length of green time based on the information of traffic volume collected by the detectors installed at the intersection. Coordinated signal control operates with pre-determined parameters such as cycle time and green time and is implemented where two interconnecting intersections are closely spaced. The concept of coordinated signal setting is illustrated in Figure 2.

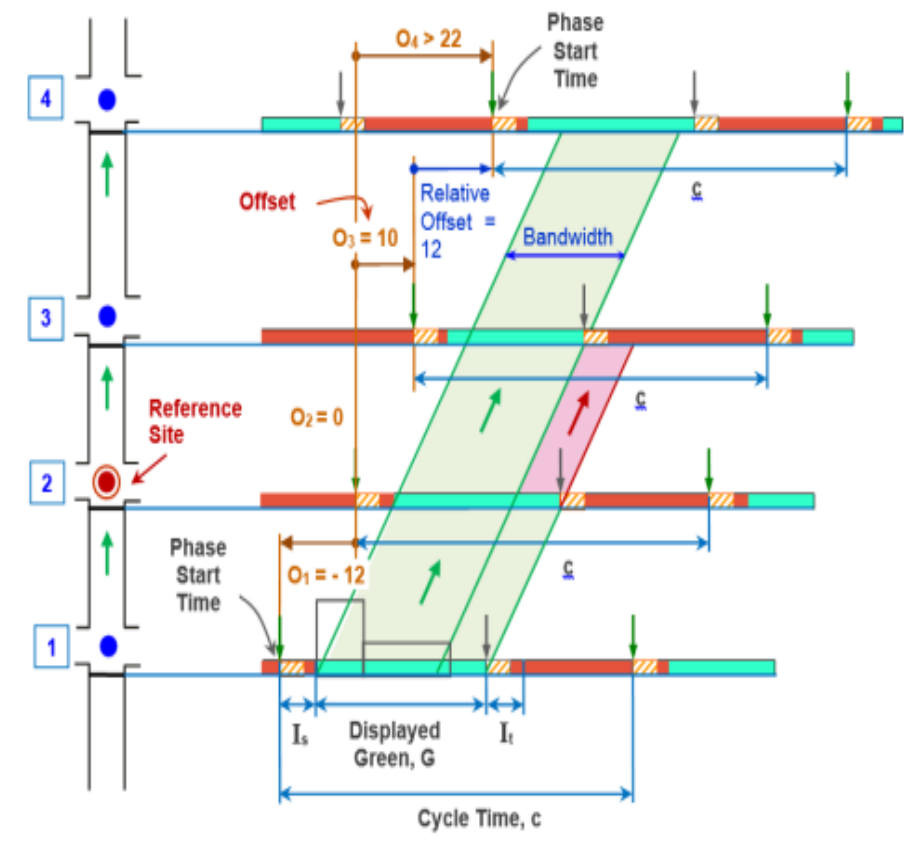

Figure 2. Illustration of Coordinated Traffic Signal Control (Akcelik, 1996)

The offset is an important parameter in a coordinated signal as it represents the time difference between the start time of the green period at the downstream intersection relative to the start time of a green period at the upstream intersection (Akcelik, 1996). As the platoons of vehicles are discharged from the upstream traffic signal at Intersection 2, the downstream signal i.e Intersection 3 is coordinated by 10 seconds of offset time to display green for the arriving vehicle platoons. This is to ensure the vehicles travel from one intersection to the other that are 
closely spaced with minimal stopping. The offset is determined based on the time taken for a vehicle to travel along with the distance between two intersections with free-flow speed.

Although this may seem beneficial in alleviating delay, there are some factors limiting the benefits of signal coordination such as inadequate roadway capacity, heavy turn volumes to or from the main street, and the existence of side frictions on the main street including loading and double parking.

Traffic signal optimization is one of the cost-effective ways to improve traffic flow at a signalized intersection. Sunkari (2004) outlined several reasons why signal optimization is required :

- Platoons of vehicles are able to travel from one intersection to the other with minimal or no stopping by coordinating a series of traffic signals.

- To accommodate traffic demand fluctuations in the different time periods of a day.

Various approaches have been attempted to coordinate a traffic signal in a traffic network corridor. Lo (2001) has adopted mixed-linear integer programming in the context of CTM. It features a high number of binary variables at the expense of large computational complexity, hence it was recommended that more heuristics approaches be developed to reduce the computational cost and time. A research conducted by Girianna \& Benekohal (2004) presented the application of the Genetic Algorithm (GA) that intelligently distributes queues over several interconnected signalized intersections. The algorithm generates optimal signal offsets along each arterial depending on the traffic demand fluctuations. It is simple and robust in which it tends to converge on solutions that were nearly optimal even in large-scale traffic applications. GA is then used by Wang et al. (2013) in CTM modeling approach to optimize traffic signals and hence minimize the average delay of the traffic network. It was found that the dynamic signal plan produced based on the algorithm has reduced the average delay of a network by 6 seconds and also in major traffic corridors by 9 seconds as compared to the fixed signal plan.

\section{Macroscopic and Microscopic Models}

Drew (1968) described simulation as "a dynamic representation of some part of the real world achieved by building a computer model and moving it through time". Since the past decades, traffic simulation had been gaining interest and widely used in traffic analysis because the process is more cost-effective, safer, and faster than field implementation and testing (Nyantakyi et al. 2014). The traffic simulation models are categorized as microscopic or macroscopic models. The microscopic model focuses on the movement of each individual vehicle proceeding close together in a single lane. The model is typically functions of velocity, position, and acceleration of each individual vehicle. It is also known as the "car-following" model as the behavior of the vehicles is dictated by a lead vehicle. The microscopic model is unique in a way that describes the driver's behavior such as lane-changing and overtaking in a traffic network, which leads to a more realistic simulation. Although researchers were interested in exploring car-following behavior through the microscopic model, modeling and tracking each individual vehicle in a large traffic network is rather time-consuming, expensive, and complicated as the simulation process will be done in real-time to ensure its accuracy (Mardiati et al. 2014). The macroscopic model is developed based on the concept of traffic flow analogous to hydrodynamic theory in one-dimensional fluids. As density and flow are continuous in temporal and spatial scale, the traffic stream is analyzed in terms of flux flow (vehicles) into and out of the system while preserving the law of conservation (Astarita 2002), hence no vehicles are lost within the road segments. The first developed macroscopic model was the LWR model (Lighthill \& Whitham, 1955; Richards, 1956), then Cell Transmission Model (Daganzo 1994) is the simplified macroscopic model originated from the LWR model. The macroscopic models simulate traffic flow based on the continuity flow equation : 


$$
q=v k
$$

Where $=$ flow rate (traffic volume), = space mean speed and density. The linear relationship between speed and density can be converted to parabolic relationship for speed and traffic flow, as well as traffic flow and density as shown in Figure 3.
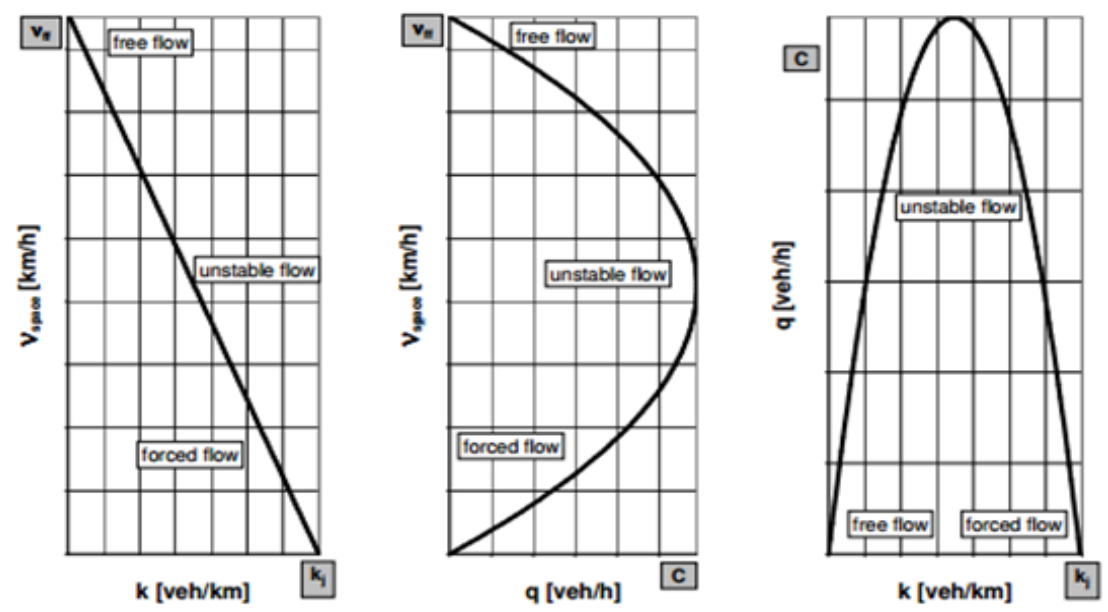

Figure 3. Traffic fundamental theory for uninterrupted traffic flow (Smit 2006)

A free flow condition where drivers travel at free-flow speed (denoted by vff in Figure $3)$, traffic volume is fairly small with low density on the road segment. As traffic volume increases, traffic flow also increases but the vehicle speed decreases as the vehicle movements are most likely restricted by the preceding vehicles. When road capacity $\mathrm{C}$ (Figure 3 ) is reached, it is the maximum traffic volume that the road segment can accommodate and the traffic condition becomes forced flow which results in vehicle queuing as they can only travel at very low speed. In the case where the jam density is reached (kj in Figure 3), the vehicles are forced to idle, and delay is propagated to the upstream link of the road segment.

\section{Cell Transmission Model (CTM)}

Cell Transmission Model proposed by Daganzo (1994) is the simplified macroscopic model that originated from the LWR model. It gathered attention in the context of traffic simulation as it is able to capture important traffic features such as kinematic waves, queue formation, the backward spread of congestion as well as dissipation (Zhu et al. 2013). In CTM, a road segment is discretized into homogeneous cells with equal length. Each cell length equals the distance traveled by a vehicle in free-flow speed in a one-time step. In the free-flow condition, the vehicles are free to move from one cell (say, cell i) to the next cell (cell i+1) within a pre-determined time step. The basic assumptions of CTM are outlined as follow :

- The size of each cell is constant throughout the road segment.

- Driver's route choice is unaffected by traffic congestion, hence no land changing behavior. 


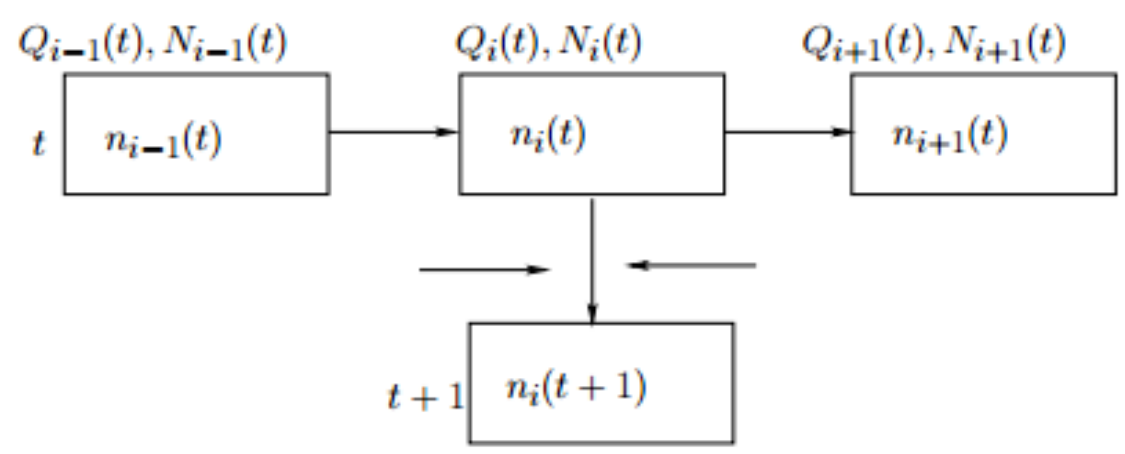

Figure 4. Flow advancement of cell in CTM (Mathew 2014)

Figure 4 shows the flow advancement of the vehicle from cell $i-1$ to cell $i$ or from cell $i$ to $i+1$ within the time step $t$. In each time step, the number of vehicles that flow into the adjacent cell is determined by the flow equation as follows.

$$
f_{i}(t)=\min \left\{n_{i-1}(t), Q_{i}(t),\left(\frac{W}{V}\right)\left[N_{i}(t)-n_{i}(t)\right\}\right.
$$

From Eqn. 2, the term [] denotes the available space in cell $i$ that is the difference between the maximum holding capacity of the cell $i$ and the number of vehicles that occupy cell $i$ at time t. In any traffic condition ranging from light flow to oversaturated flow, the vehicle flow is always taken as the minimum between the number of vehicles waiting to enter cell $\mathrm{i}$ from cell $\mathrm{i}-1$ : , the inflow capacity of cell i: and available space in cell $\mathrm{i}$. Having calculated the flow, cell occupancy can be determined using Eqn. 3:

$$
n_{i}(t+1)=n_{i}(t)+f_{i}(t)-f_{i+1}(t)
$$

Delay in CTM is defined as the additional time beyond free-flow travel time that a vehicle stays in a cell (Lo, 1999). This means that if the outflow of cell $i$ at time step $t$ is less than the current cell occupancy, the queue starts forming within the cell and the vehicles incur a delay of one-time step. The delay of an individual cell is calculated using Eqn. 4 :

$$
d_{i}(t)=n_{i}(t)-f_{i+1}(t)
$$

By aggregating the delay of each cell in the network for all time steps, the total delay of the traffic network can be estimated as shown in Eqn. 5.

$$
\text { Total Delay }=\sum_{i} \sum_{t} d_{i}(t)
$$

According to Balijepalli et al. (2014), CTM is an appropriate tool for analyzing the network which has a fixed bottleneck location and it was assumed that the congestion will only begin at the downstream intersections. In cases where there are unexpected occurrences of incidents such as bad weather conditions (snow or rain), this assumption would not be valid as the bottleneck will form at any location and CTM is not the optimal modeling tool for analyzing moving bottlenecks. Hence in this research, it was assumed that the congestion occurs due to the effect of traffic signal control as well as temporal variation in traffic demand.

\section{Improvement to CTM : CCTM}

Spillback occurs when a driver decides to move forward and queue after the last cell in downstream intersection although all the cells within the next intersection are fully occupied during the green time. To cater to the occurrence of spillback, Wang (2010) proposed an improved model to the CTM: Conditional Cell Transmission Model (CCTM) where a conditional cell is added between two intersections in the simulation scenario. This modeling approach captures more accurate congestion dynamic as spillback is also the cause of the large 
part of the collective delays experienced aside from delays caused by the formation of a bottleneck (Knoop et al. 2008). The conditional cell is formulated such that it receives traffic flow only when all the cells at a downstream intersection are fully occupied. Although in reality the drivers may or may not break the driving rule by blocking the intersection during congestion, the proposed conditional cell in CCTM depicts that the driver breaks the driving rule which reflects the psychological traits of most drivers in a real scenario.

\section{Analytical Software Model for Evaluating Signalized Intersections}

As CCTM is developed further to capture blockage, spillback, and queue in oversaturated condition at signalized intersections, a computerized macroscopic traffic model has to simulate traffic flow in a similar manner by considering the formation and dispersion of vehicle platoons such that its output can be compared to that of CCTM in this research. There are several conventional analytical software models that are able to estimate performance measures of signalized intersections in terms of delay, level of service, back of the queue, and signal optimization such as TRANSYT, SYNCHRO, and SIDRA.

TRANSYT-7F (TRAffic Network StudY Tool) utilizes a platoon dispersion model that simulates normal dispersion of vehicle platoons traveling along with a link, which consists of an aggregation of lane groups in a single network with small time increments. In each simulation step and for each link, TRANSYT-7F keeps track of the arrival and departure rate of traffic volume, uniform queue length, and back of queue movement. Its latest release (Release 8) has several improvements in handling saturated conditions such as vehicle spillback, intersection blocking, and optimization strategies for saturated conditions. Even so, the model assumes homogeneous traffic flow, and this raises doubt when there is heterogeneity in platoon dispersion i.e. mixed traffic flow when there is a high volume of bus traffic aside form car flow. Due to lower maneuverability and frequent stops at bus stations, there are some unique features in bus platoon compared to car platoon which is expected to affect the macroscopic performance in platoon dispersion behavior (Wu et al. 2015). As for signal timing optimization, the software model is set to simulate every possible signal timing plan and then choosing the final signal timing plan that is most desired. TRANSYT-7F adopts a hill-climb optimization search technique in signal optimization, which produces desired signal output according to the user-defined objective function. Users can select whether to minimize or maximize the objective function known as the performance index (PI), which is the combination of delay, progression opportunities, or optionally selected maximum back of the queue (Wallace et al. 1984). Although it is able to emulate actuated signal control, it does not optimize phase order.

SYNCHRO is also a macroscopic analysis and optimization software that requires mostly the same traffic flow data as TRANSYT-7F. Unlike TRANSYT-7F, it is able to optimize phase sequence along with other signal parameters such as offsets, cycle length, and splits. In contrast to the hill-climb method, SYNCHRO optimizes signal timing by percentile method. The concept of the percentile method can be explained in optimizing say, splits in which SYNCHRO seeks to provide adequate green time to serve $90 \%$ of vehicle flow from a lane group. If the cycle time is inadequate to serve $90 \%$ flow, successive flow percentile such as $70 \%$ and $50 \%$ flow is then attempted (Husch \& Albeck 2003).

While these network models sound promising in evaluating signalized intersections and signal optimization, they cannot conduct lane-by-lane analysis as they model traffic flow at link (lane groups) level in the traffic network. As a link represents an aggregation of individual lanes conditions, it cannot provide a realistic estimation of upstream departure and downstream arrival patterns as well as queue and spillback at the individual lane level. This is particularly crucial in providing reliable network performance modeling because, in real traffic scenarios, unequal lane utilization often results in a different extent of the delay, queue, and level of 
service in traffic network (Akcelik 2014). This in turn affects the signal timing plan especially at closely-spaced intersections where there is high demand flow. Likewise, CTM analyses the network at an individual cell level, which can be summed up to reflect a different level of delay and queue length in each individual lane.

Developed by Akcelik (1996), SIDRA (Signalized and Unsignalized Intersection Design and Research Aid) software adopts a lane-based model that models a second-by-second departure and arrival flow rates of individual lanes at the upstream and downstream intersection. Aside from that, the lane-based model also takes into consideration of backward spread of queue between intersections and capacity-reducing constraints at upstream lanes due to downstream spillback in relation to oversaturated conditions. To investigate the implications of the lane-based model on signal platooning and resulting performance measures, Akcelik (2014) has utilized SIDRA to implement various analysis scenarios by applying default lane movement flow proportion (100\% flow for all lanes) and unequal lane flow proportion (40\%-60\% and $70 \%-30 \%$ flow) at two-way two-lane signalized staggered $\mathrm{T}$ intersections. A fixed network cycle of 100 seconds is applied to all scenarios with green split priority in SIDRA. As a result, the scenario with unequal lane use has a longer green time priority for the lane that carries more flow than the other under-utilized lane. There are also notable dissimilarities in platoon characteristics modeled per lane and per movement (higher platoon ratio for heavily used through movement indicating more percentage of vehicles arriving during the green period). This contributed to significantly different performance measures such as a larger 95 percentile back of the queue and average delay per lane and per movement basis.

To demonstrate the key characteristics of these analytical software models, Table 2 shows the summary of applications that each analytical software is capable of modeling. Although these models are also able to model emission and fuel consumption it is not within this research scope and hence is not listed in this table. Considering that only SIDRA carries out the more implicit lane-based modeling that analyses individual lanes which are closely related to the methodology used in CTM simulation, it is chosen as the analytical software to carry out signal optimization as well as to compare and contrast its delay and LOS output against CTM.

Table 1. Characteristics of Different Analytical Software Models.

\begin{tabular}{|c|c|c|c|c|c|c|c|c|}
\hline \multirow{2}{*}{$\begin{array}{c}\text { Analytic } \\
\text { al } \\
\text { Software } \\
\text { Model }\end{array}$} & \multicolumn{3}{|c|}{ Performance Measures } & \multicolumn{4}{|c|}{ Signal Optimization } & \multirow{2}{*}{$\begin{array}{c}\text { Lane-by- } \\
\text { Lane } \\
\text { Analysis }\end{array}$} \\
\hline & Delay & $\begin{array}{c}\text { LO } \\
\mathbf{S}\end{array}$ & Queue & $\begin{array}{c}\text { Cycle } \\
\text { Lengt } \\
\text { h }\end{array}$ & $\begin{array}{c}\text { Spli } \\
\text { t }\end{array}$ & $\begin{array}{c}\text { Phase } \\
\text { Sequenc } \\
\text { e }\end{array}$ & $\begin{array}{c}\text { Coordinate } \\
\text { d signal }\end{array}$ & \\
\hline $\begin{array}{c}\text { TRANSY } \\
\text { T-7F }\end{array}$ & $\begin{array}{l}\text { Total } \\
\text { delay }\end{array}$ & Yes & $\begin{array}{l}\text { Maximum } \\
\text { back of the } \\
\text { queue }\end{array}$ & Yes & Yes & No & Yes & No \\
\hline $\begin{array}{c}\text { SYNCHR } \\
\text { O }\end{array}$ & $\begin{array}{l}\text { Total } \\
\text { delay }\end{array}$ & Yes & $\begin{array}{l}\text { Maximum } \\
\text { queue } \\
\text { length }\end{array}$ & Yes & Yes & Yes & Yes & No \\
\hline $\begin{array}{c}\text { SIDRA } \\
\text { Intersectio } \\
\mathrm{n}\end{array}$ & $\begin{array}{l}\text { Stoppe } \\
\text { d delay } \\
\text { and } \\
\text { total } \\
\text { delay }\end{array}$ & Yes & $\begin{array}{c}\text { Maximum } \\
\text { back of } \\
\text { queue and } \\
\text { percentile } \\
\text { queue } \\
(90 \%, \\
95 \%, \text { and } \\
98 \%)\end{array}$ & Yes & Yes & Yes & Yes & Yes \\
\hline
\end{tabular}




\section{METHODOLOGY}

\section{Traffic Data Collection}

Prior to simulating traffic flow using CTM, a field survey is conducted at the two-lane and two-way signalized intersections with a fixed signal setting. Three connected signalized intersections located along Jalan Lagoon Selatan, Bandar Sunway (Figure 5) are chosen to conduct traffic data collection due to its proximity to highly concentrated residential and commercial area which services high traffic flow. From the brief observation in morning peak hour, vehicle queuing at the intersection occurs and the signal time does not readjust to the approaching traffic volume. The arterial road is mostly highly congested, causing delay and spillback to incur at intersections.

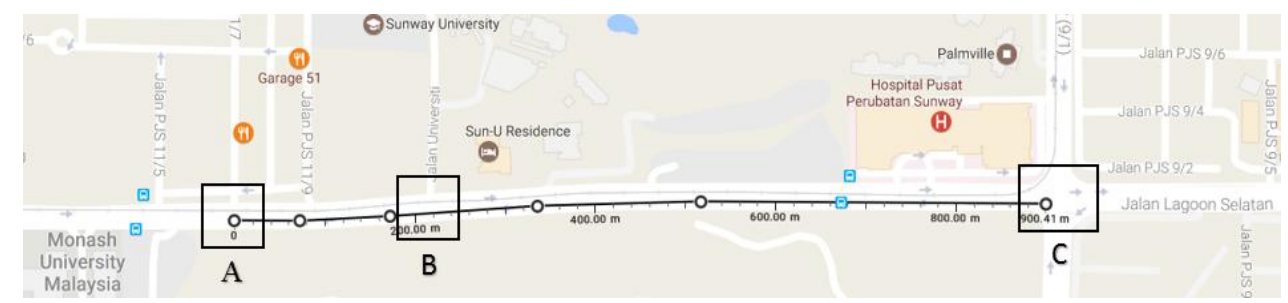

Figure 5. Location of field data collection along Jalan Lagoon Selatan comprising 3 interconnecting intersections $\mathrm{A}, \mathrm{B}$, and $\mathrm{C}$.

Video cameras were used to record the traffic flow at three intersections spaced approximately $900 \mathrm{~m}$. From Figure 5, Intersection A is the intersection prior to reaching Monash University Malaysia, Intersection B is located nearby Sunway University and Intersection C is located within the vicinity of Sunway Medical Centre. Geometric wise, intersection A is a fourlegged signalized intersection with slip lanes in each approach leg, whereas B and C are threelegged intersections. Four observers were present to manage the video camera setup as well as carry out field observation on the operational conditions in each intersection simultaneously. The data collection was conducted for 20 minutes, with the collected data summarized as follows :

- Classified vehicle count (light and heavy vehicles)

- Existing signal timing and phasing

- Turning movement counts at the intersection

- Observation on vehicle spillbacks

- Observation on vehicle lane changing

It was found that Intersection A and B operate on pre-timed signal whereas Intersection $\mathrm{C}$ has actuated signal control with varying green time in all approaches.

\section{CTM Simulation}

The simulation theory of CTM is applied in Excel to emulate the traffic scenario. First, the analysis period of interest is divided into 200 intervals with 6 seconds in each time step that sums up to 20 minutes as per data collection. The traffic parameters for CTM are set in Table 3. 
Table 2. Parameters that define the traffic network in CTM

\begin{tabular}{ll}
\hline Basic parameters & Assigned value \\
\hline Timestep, T & $6 \mathrm{~s}$ \\
Free-flow speed, V & $51 \mathrm{~km} / \mathrm{h}$ \\
Saturation flow rate, S & 1800 vehicles/hour \\
Jam density, jam & 102 vehicles/km/lane \\
Flow capacity, Q & 3 vehicles/time step/lane \\
Cell length, L & $85 \mathrm{~m}$ \\
Maximum holding capacity, N & 8 vehicles/cell \\
\hline
\end{tabular}

Flow capacity, $\mathrm{Q}$ is the product of saturation flow rate and length of time step :

$Q=S \times T$

The cell length is the product of free-flow speed and length of time step:

$L=V \times T$

The maximum holding capacity of each cell is calculated as follows:

$$
N=L \times k_{\text {jam }}
$$

The modeling of CTM focuses on the two-lane urban arterial (Jalan Lagoon Selatan) that accommodates vehicles traveling along an eastbound direction from Sunway Medical Centre to Monash University Malaysia. Link 1 connects Intersection C to Intersection B, whereas Link 2 connects Intersection B to Intersection A (Figure 6).

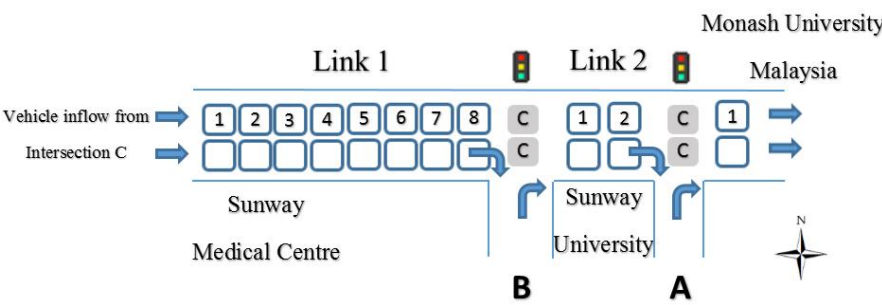

Figure 6. Components of Link 1 and Link 2 consisting of uniform cells and conditional cells

The length of Link 1 is set as $680 \mathrm{~m}$ long and discretized into 8 uniform cells of $85 \mathrm{~m}$. Link 2 spans $210 \mathrm{~m}$ and is divided into 2 cells of $85 \mathrm{~m}$ with a conditional cell (labeled as " $\mathrm{C}$ " in Figure 6) of $40 \mathrm{~m}$ in each lane to simulate spillback. Lane 1 permits only through movement whereas Lane 2 provides southbound turning movement at Intersection A and B.

An entry gate cell is added before the first cell in Link 1 to store and input traffic demand to the traffic network (Figure 7). The input traffic demand released within each time step is based on the traffic volume entering Link 1 during 20-minute data collection. 


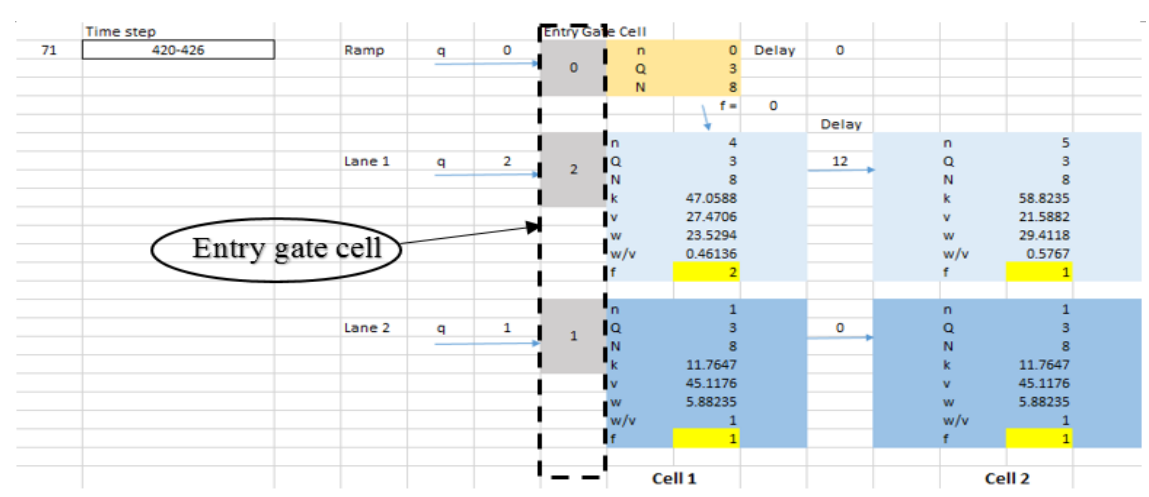

Figure 7. Screenshot of CTM simulation at the 71st-time step.

The propagation of vehicle flow from one cell to the other is modeled using a flow equation (Eqn. 2). From Eqn. 2, the W/V ratio (ratio of shockwave speed to free-flow speed) varies depending on the cell occupancy.

When the number of vehicles increases within a cell, density, $\mathrm{k}$ increases as the spacing between vehicles become narrower, hence affecting its free-flow speed. The current operational free-flow speed can be determined using Eqn. 9 :

$$
v_{1}=\left[1-\frac{k_{1}}{k_{\text {jam }}}\right] \times v_{f f}
$$

where is calculated using Eqn. 8 and $=51 \mathrm{~km} / \mathrm{h}$. The shockwave speed can then be determined using Eqn. 10:

$$
W=\frac{q_{1}-q_{\text {sat }}}{k_{1}-\text { jam }}
$$

where is calculated using Eqn. 1 and $=1800$ vehicles $/ \mathrm{h}$. The W/V ratio determined from the ratio of shockwave speed current operational free-flow speed affects the output flow into the next cell in the following time step. In Excel, signal control is assigned as 1 for green time whereas 0 for red time which is multiplied to the flow equation in Cell 8 in Link 1 and Cell 2 in Link 2 for both lanes to allow or stop vehicle flow. A conditional cell is modeled in Excel and the concept of flow is illustrated in Figure 8.

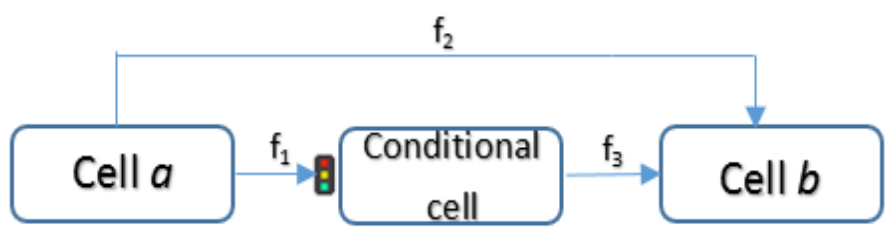

Figure 8. Flow mechanism of the conditional cell.

When the signal is green, the flow into cell $\mathrm{b}$ is $\mathrm{f} 2$ provided there are available spaces in cell $b$ to accommodate vehicles from the cell $a$. If cell $b$ is fully occupied (say, 8 vehicles), $a$ conditional cell is triggered to hold spillback vehicles originating from the cell a. This means that the outflow into cell $\mathrm{b}$ occurs via $\mathrm{f} 1$ then followed by $\mathrm{f} 3$. The flow formulae are outlined as follow :

$$
\begin{aligned}
& f_{1}=\min \left(n_{a}, Q_{\text {con }},\left(N_{\text {con }}-n_{\text {con }}\right)\right) \\
& f_{2}=\min \left(n_{a}, Q_{b},\left(N_{b}-n_{b}\right)\right) \\
& f_{3}=\min \left(n_{\text {con }}, Q_{b},\left(N_{b}-n_{b}\right)\right)
\end{aligned}
$$


Delay within each cell is determined using Eqn. 4 and the hence total delay by aggregating all the cells over 200-time steps (Eqn. 5). The average control delay is calculated using Eqn. 14:

$$
\text { Average control delay }=\frac{\sum_{i} \sum_{t} d_{i}(t)}{\sum_{t} f_{i}(t)}
$$

Based on the estimated average control delay, LOS is determined by referring to Table 1.

\section{Computational Analysis}

The performance of CTM in delay estimation is validated by using analytical software Signalized and Unsignalized Intersection Design and Research Aid (Akcelik 1996) to analyze the network of intersections A, B, and C. The simulation runs on the input defined by the user via the "Site Input" interface. For each intersection, the user-defined site inputs are intersection and lane geometry, movement definition (light or heavy vehicles), lane data (input of saturated flow rate), traffic volume data and signal phasing and timing information obtained from data collection. A network is constructed and demonstrated in SIDRA

as shown in

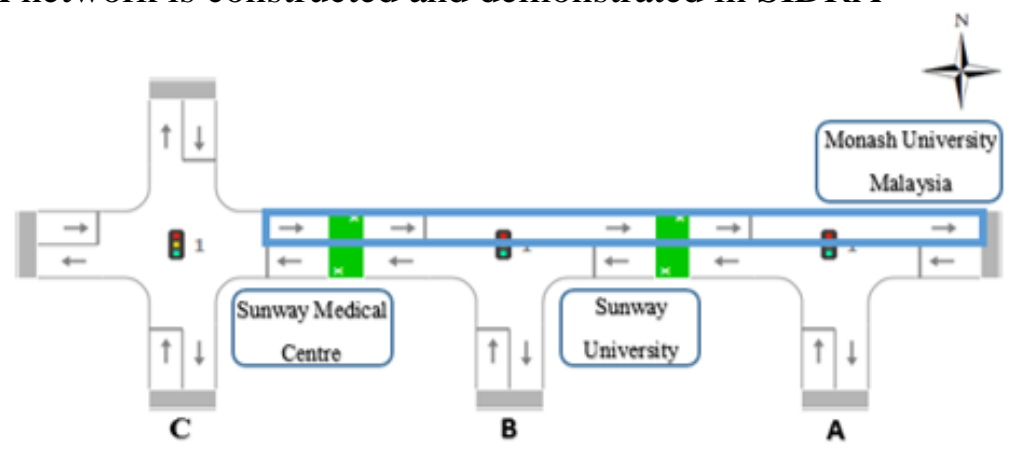

Figure 9.

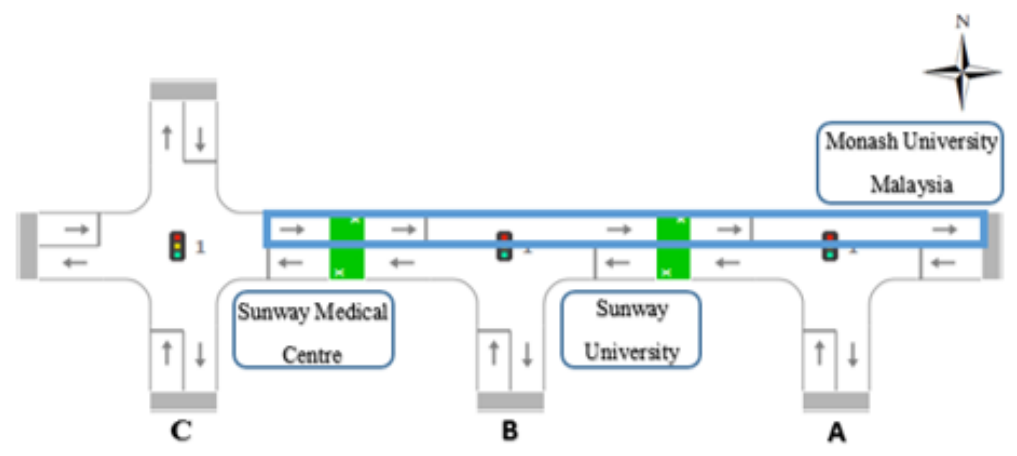

Figure 9. Network configuration comprising Intersection A, B, and C in SIDRA. 


\begin{tabular}{|c|c|c|c|c|}
\hline Intersection & Phase sequence & Movements & Description & $\begin{array}{l}\text { Displayed green } \\
\text { time (seconds) }\end{array}$ \\
\hline \multirow[t]{3}{*}{ A } & 1 & $\Longrightarrow$ & Eastbound & 54 \\
\hline & 2 & & $\begin{array}{l}\text { Eastbound } \\
\text { and } \\
\text { Southbound }\end{array}$ & 48 \\
\hline & 3 & $\overrightarrow{6} \vec{\Gamma}$ & $\begin{array}{l}\text { Eastbound } \\
\text { and } \\
\text { Westbound }\end{array}$ & 48 \\
\hline \multirow[t]{3}{*}{ B } & 1 & & $\begin{array}{l}\text { Eastbound } \\
\text { and } \\
\text { Southbound }\end{array}$ & 54 \\
\hline & 2 & $\Longrightarrow$ & Eastbound & 84 \\
\hline & 3 & & $\begin{array}{l}\text { Eastbound } \\
\text { and } \\
\text { Westbound }\end{array}$ & 54 \\
\hline \multirow[t]{4}{*}{$\mathrm{C}$} & 1 & & $\begin{array}{l}\text { Eastbound } \\
\text { and } \\
\text { Southbound }\end{array}$ & Actuated \\
\hline & 2 & & $\begin{array}{l}\text { Southbound } \\
\text { and } \\
\text { Westbound }\end{array}$ & Actuated \\
\hline & 3 & & $\begin{array}{l}\text { Northbound } \\
\text { and } \\
\text { Eastbound }\end{array}$ & Actuated \\
\hline & 4 & $\stackrel{0}{\rightleftarrows}$ & $\begin{array}{l}\text { Westbound } \\
\text { and } \\
\text { Northbound } \\
\text { with U-turn }\end{array}$ & Actuated \\
\hline
\end{tabular}

Figure 10. Signal phasing summary for Intersection A, B, and C

\section{DISCUSSION AND RESULTS}

\section{Delay and Level of Service (LOS)}

\section{Baseline Experiment}

The delay obtained is based on the highest average delay within 200-time steps in each lane, and the approach summary represents the overview of delay and LOS based on evaluation of delay for both lanes in all time steps.

Table 3. Intersection and LOS summary in CTM

\begin{tabular}{cccc}
\hline Intersection & Lane/Approach & Delay (seconds) & LOS criteria \\
\hline \multirow{2}{*}{$\mathrm{A}$} & Lane 1 & 91.6 & $\mathrm{~F}$ \\
\cline { 2 - 4 } & Lane 2 & 66.7 & $\mathrm{E}$ \\
\cline { 2 - 4 } & Approach & 55 & $\mathrm{D}$ \\
\hline \multirow{2}{*}{$\mathrm{B}$} & Lane 1 & 365.7 & $\mathrm{~F}$ \\
\cline { 2 - 4 } & Lane 2 & 116.2 & $\mathrm{~F}$ \\
\cline { 2 - 4 } & Approach & 235 & $\mathrm{~F}$ \\
\hline
\end{tabular}

From Table 4, the urban arterial was found to be operating at mostly LOS F, which provides an accurate prediction on the observed operational condition from data collection where most lanes are highly congested and queues fail to clear within one cycle. In order to test the statistical performance of CTM in delay estimation, the results of the simulation are compared to SIDRA as an analytical tool with same input parameters (hourly traffic volume, free-flow speed, saturation flow, existing signal phasing, and timing) and the results are tabulated in Table 5 .

Table 4. Intersection and LOS summary in SIDRA

\begin{tabular}{|c|c|c|c|c|}
\hline Intersection & Lane/Approach & $\begin{array}{c}\text { Delay } \\
\text { (seconds) }\end{array}$ & LOS criteria & $\begin{array}{l}\text { Percentage } \\
\text { difference }\end{array}$ \\
\hline
\end{tabular}




\begin{tabular}{ccccc}
\hline & & & & $\begin{array}{c}\text { compared to } \\
\text { CTM }\end{array}$ \\
\hline \multirow{3}{*}{ A } & & & & B \\
\cline { 2 - 5 } & Lane 1 & 16 & E & $23 \%$ \\
\cline { 2 - 5 } & Lane 2 & 51.6 & C & $50 \%$ \\
\hline \multirow{2}{*}{ B } & Approach & 27.4 & F & $13 \%$ \\
\cline { 2 - 5 } & Lane 1 & 419.2 & F & $9 \%$ \\
\cline { 2 - 5 } & Lane 2 & 105.7 & F & $26 \%$ \\
\hline
\end{tabular}

From Table 5, CTM yields similar output as SIDRA in delay estimation at Intersection $\mathrm{B}$, however, delay differs by a large margin particularly in Lane 1 of Intersection A with significantly distinct LOS as compared to CTM. This is not entirely consistent with field data collection as the observation of delay tends to be in LOS C or D where the vehicles experience tolerable delay or occasional waiting for more than one cycle before proceeding. Technically wise, as SIDRA analyses a network as a whole consisting of all the intersections A, B, and C, the high traffic volume originated from Intersection $\mathrm{C}$ causes the upstream lanes at Intersection B to become oversaturated. SIDRA automatically applies this capacity constraint to reduce the downstream arrival flow at Intersection A, hence causing the delay to be much lower. The degree of saturation of Lane 1 was found to be only 0.47 from SIDRA, which indicates low volume to capacity ratio $(\mathrm{v} / \mathrm{c})$ within the road segment and it is unlikely for congestion to occur. As opposed to SIDRA, there is no capacity constraint parameter allocated in CTM to reduce incoming traffic volume as flow conservation is assumed for all vehicles entering the traffic network. The rate of flow is only dependent on the number of vehicles in each cell that affects the density and shockwave speed which determines the extent of delay in each cell. The higher the number of vehicles in the cell, the higher the density and backward shockwave speed and hence higher delay within the cell. This explains why the aggregated delay from all cells in Intersection A generated a high overall delay when arrival flow is conserved throughout the link of cells. While SIDRA underestimates the delay as compared to field observation, CTM may slightly overestimate delay but it provides a useful prediction on the signalized arterial's level of service criteria.

Another reason for the difference in delay estimation in CTM compared to SIDRA is the coverage of input parameters in the analysis. Although SIDRA contains the basic input parameters as CTM such as saturation flow rate, free-flow speed, hourly traffic volume and distance between intersections, it provides a wider coverage of adjustment factors that are either user-specified or program-determined such as lane width, bus blockage, and lane utilization ratio that caters for unequal distribution of traffic flow. These adjustment factors are yet to be developed and applied in CTM, which is the limitation of the modeling approach in delay estimation.

\section{Traffic Signal Optimization Analysis}

The signal coordination in SIDRA was conducted based on a fixed network cycle of 250 seconds. From Figure 11, the phase split allocates higher weightage on through and turning movements in order to accommodate high input traffic volume, resulting in relatively long allocated green time in Phase 1 and Phase 2 for both intersections. The phase split includes the inter-green period which comprised of yellow time (4 seconds) and an all-red period ( 1 second) based on-site observation. This coordinated signal time replaces the existing input signal 
parameter in CTM and the estimated delay and LOS is compared to delay output in SIDRA in Table 6.

\begin{tabular}{|c|c|c|c|c|c|c|}
\hline Intersection & $\begin{array}{c}\text { Phase } \\
\text { sequence }\end{array}$ & Movements & Description & $\begin{array}{l}\text { Displayed } \\
\text { green time } \\
\text { (seconds) }\end{array}$ & $\begin{array}{l}\text { Phase } \\
\text { time } \\
\text { (seconds) }\end{array}$ & $\begin{array}{c}\text { Phase split } \\
(\%)\end{array}$ \\
\hline \multirow[t]{3}{*}{ A } & 1 & $\Longrightarrow$ & Eastbound & 108 & 113 & $45.4 \%$ \\
\hline & 2 & $\vec{b}$ & $\begin{array}{l}\text { Eastbound } \\
\text { and } \\
\text { Southbound }\end{array}$ & 108 & 113 & $45.4 \%$ \\
\hline & 3 & $\Leftrightarrow \vec{\Gamma}$ & $\begin{array}{l}\text { Eastbound } \\
\text { and } \\
\text { Westbound }\end{array}$ & 18 & 23 & $9.2 \%$ \\
\hline \multirow[t]{3}{*}{ B } & 1 & $\vec{b}$ & $\begin{array}{l}\text { Eastbound } \\
\text { and } \\
\text { Southbound }\end{array}$ & 48 & 53 & $43 \%$ \\
\hline & 2 & $\Rightarrow$ & Eastbound & 36 & 41 & $33 \%$ \\
\hline & 3 & $\Leftrightarrow \vec{C}$ & $\begin{array}{l}\text { Eastbound } \\
\text { and } \\
\text { Westbound }\end{array}$ & 24 & 29 & $24 \%$ \\
\hline
\end{tabular}

Figure 11. Coordinated signal phasing and timing recommended by SIDRA

Table 5. Comparison of delay and LOS output

\begin{tabular}{|c|c|c|c|c|c|c|c|}
\hline \multirow[b]{2}{*}{ Intersection } & \multirow[b]{2}{*}{$\begin{array}{c}\text { Lane/ } \\
\text { Approach }\end{array}$} & \multicolumn{3}{|c|}{ CTM } & \multicolumn{3}{|c|}{ SIDRA } \\
\hline & & $\begin{array}{c}\text { Baseline } \\
\text { experiment }\end{array}$ & $\begin{array}{c}\text { Optimized } \\
\text { signal } \\
\text { setting } \\
\end{array}$ & $\begin{array}{c}\text { Delay } \\
\text { reduction } \\
\text { /increase }\end{array}$ & $\begin{array}{c}\text { Baseline } \\
\text { experiment }\end{array}$ & $\begin{array}{c}\text { Optimized } \\
\text { signal } \\
\text { setting } \\
\end{array}$ & $\begin{array}{c}\text { Delay } \\
\text { reduction } \\
\text { /increase }\end{array}$ \\
\hline \multirow[t]{6}{*}{$\mathrm{A}$} & Lane 1 & 91.6 & 68.4 & 23.2 & 16.0 & 10.7 & 5.3 \\
\hline & & LOS F & LOS E & $(-25.3 \%)$ & LOS B & LOS B & $(-33.1 \%)$ \\
\hline & Lane 2 & 66.7 & 45.6 & 21.1 & 51.6 & 93.3 & 41.7 \\
\hline & & LOS E & LOS D & $(-31.6 \%)$ & LOS D & LOS F & $\begin{array}{c}(+ \\
44.7 \%) \\
\end{array}$ \\
\hline & Approach & 55 & 41 & 14 & 27.4 & 37.1 & 9.7 \\
\hline & & LOS D & LOS D & $(-25.5 \%)$ & LOS C & LOS D & $(+26.1 \%)$ \\
\hline \multirow[t]{6}{*}{ B } & Lane 1 & 365.7 & 304.6 & 61.1 & 419.2 & 96.4 & 322.8 \\
\hline & & LOS F & LOS F & $(-16.7 \%)$ & LOS F & LOS F & $(-77 \%)$ \\
\hline & Lane 2 & 116.1 & 75.9 & 40.2 & 105.7 & 49.5 & 56.2 \\
\hline & & LOS F & LOS E & $(-34.6 \%)$ & LOS F & LOS D & $(-53.2 \%)$ \\
\hline & Approach & 235 & 195 & 40 & 318.9 & 81.4 & 237.5 \\
\hline & & LOS F & LOS F & $(-17 \%)$ & LOS F & LOS F & $(-74.5 \%)$ \\
\hline
\end{tabular}

CTM generates overall positive results in delay reduction in all lanes for both intersections, however, the reduction is not significant i.e. 61.1 seconds in Lane 1 of Intersection $\mathrm{B}$ as compared to 322.8 seconds reduction in delay from SIDRA. Although having minor LOS improvement in Lane 2, the LOS of the overall approach in Intersection B remained at LOS F for both outputs of CTM and SIDRA. This shows that the coordinated traffic signal is able to alleviate delay at a signalized intersection but in the case of urban arterial suffering from massive delay, a coordinated signal may not be able to improve the road's operational condition and level of comfort of the drivers. 
Another interesting output for discussion is the increase in delay by 41.7 seconds in Lane 2 of Intersection A and an overall $26.1 \%$ increase in delay at the signalized approach. Located at downstream of the traffic network, the signals in Intersection A run on a fixed cycle length (250 seconds) as Intersection B. While this fixed cycle length favors delay reduction in Intersection B that is located upstream, the signal progression is not as efficient and sufficient to Intersection A which now caters to a higher arriving platoon of vehicles due to more vehicles discharging from Intersection B. Due to longer cycle length the arriving vehicles spend a longer time in a queue waiting for the signal to turn green. In order to ensure the signal time coordination achieves full optimization, other traffic signal parameters such as cycle length and offset have to be examined while considering the spacing between two intersections.

To illustrate the effect of coordinated signal timing on delay alleviation in CTM, Figure 12 and Figure 13 represents the summarized average delay per vehicle within 20 minutes (200 time steps evolution) in Intersection A and Intersection B respectively.

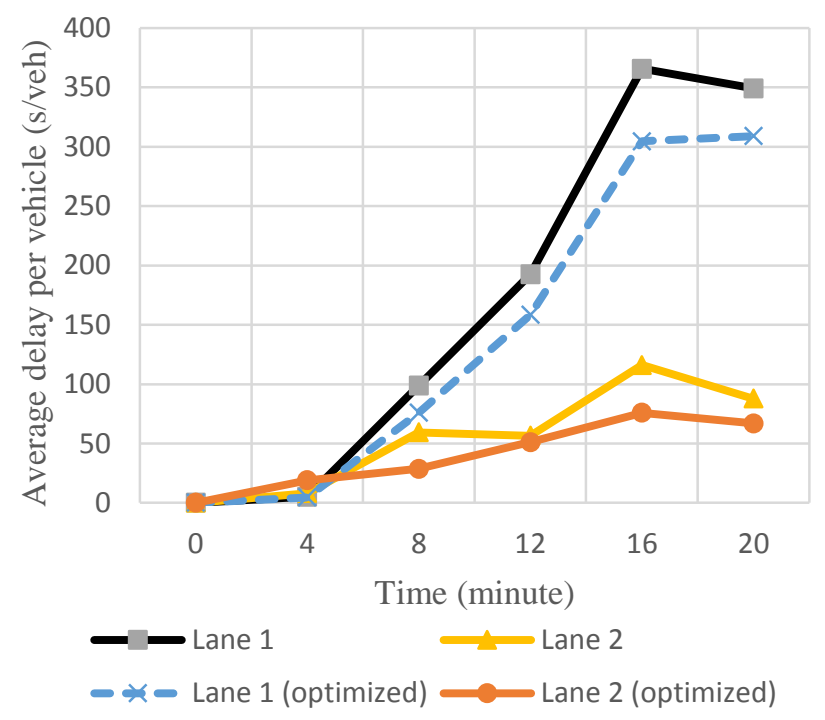

Figure 12. Average delay per vehicle in Intersection A

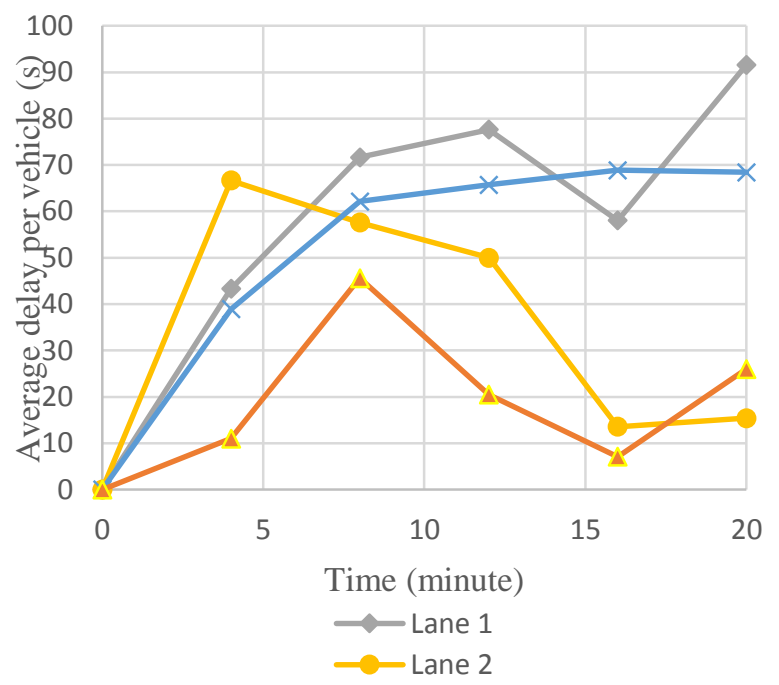

Figure 13. Average delay per vehicle in Intersection B 
The optimized signal timing that emphasizes on through and turning movement yields lower average delay in all lanes which is consistent with the theoretical prediction. From Figure 12 , although there is an increase in average delay in the 20th minute for optimized Lane 2, the average delay peaks at a later time compared to Lane 2 with an existing signal time setting.

As for Figure 13, average delay peaks at 16th minute for all lanes followed by a drop at the end of the 20th minute. The propagation of average delay in CTM is highly dependent on the stochastic traffic demand which is collected from data collection and converted into the input demand in different time steps. At time steps where the input traffic demand is high and a signal is red, the first batch of vehicles arriving at the signal are obliged to stop with no outflow to a downstream intersection, and delay starts accumulating in the cell. As the signal remains red, delay propagates to upstream cells as more cells are fully occupied with the vehicles.

\section{Shockwave Speed Evolution in CTM}

The density within each cell in CTM correlates directly with the shockwave speed (). The higher the number of vehicles within a cell, the higher the density and hence higher shockwave speed that causes the platoon of vehicles to form backward to upstream cell i.e. cell i- 1 . As the conventional CTM in the past research relies on a fixed $\mathrm{W} / \mathrm{V}$ ratio in flow computation, this research proposes a variability in shockwave speed in flow advancement of vehicles in each cell within the simulation time steps. The larger the platoon of vehicles, the slower the flow advancement of vehicles into cell $i+1$ from cell $i$. The methodology of simulating flow adaptation to varying shockwave speed is explained in Section 3.2. The evolution of shockwave speed at Intersection A is illustrated in the Figure 14.

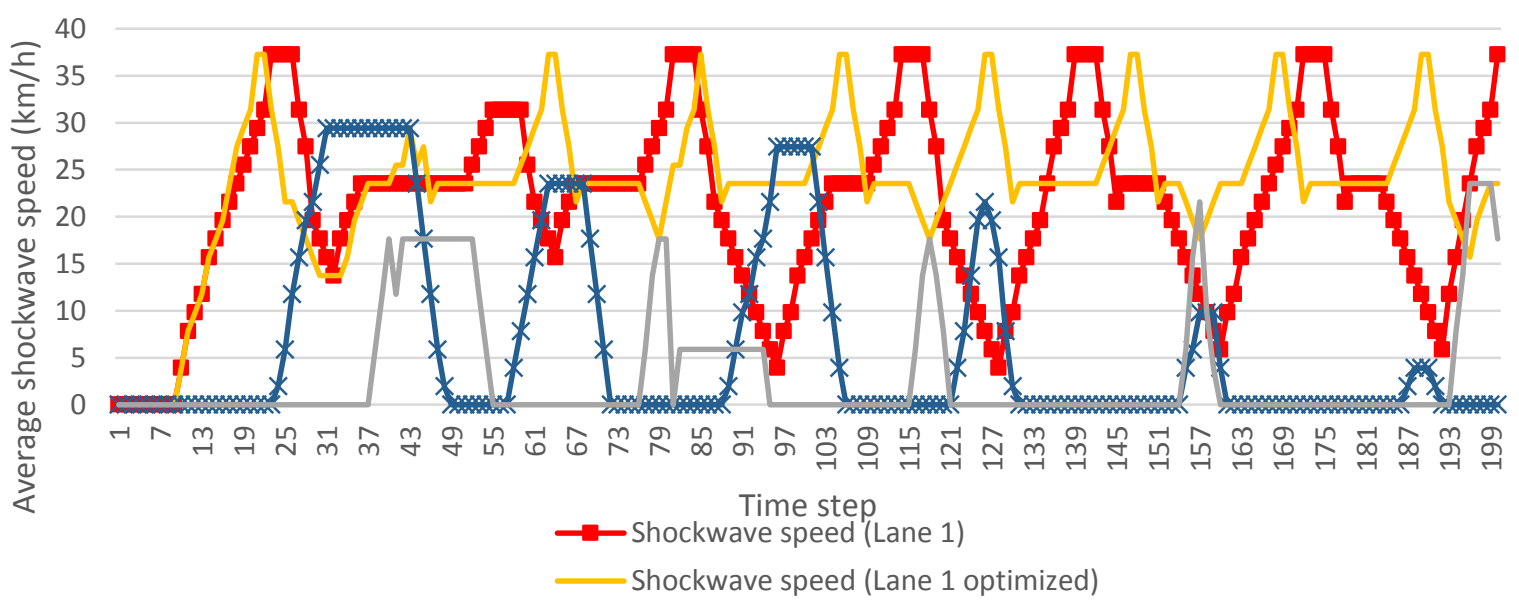

Figure 14. Propagation of shockwave speed in Intersection A

From Figure 14, the rising and falling trend of average shockwave speed within 200-time steps provides an insight on the rate of queue or platoon forming and dissipation at Intersection A. When the shockwave speed is 0 , the vehicles flow from one cell to the other with no delay. When more vehicles enter the cell and the increase in density causes the vehicles to travel at speed lower than their free-flow speed, shockwave speed develops uniformly as time step progresses. The rate of increase in shockwave speed indicates the rate of platoon formation and the decrease in shockwave speed indicates lower density in all cells, hence there is platoon dispersion.

A comparison is made between the average shockwave speed at Intersection A before signal optimization and after optimization. The average shockwave speed in the optimized lanes has lower peaks and occurs at a later time step compared to those without signal optimization. 
It indicates that the queue formation occurs at a slower rate and fewer vehicles queuing that contributes to delay in the aggregated cell network.

\section{Discussion on Model Strength and Limitation}

CTM is developed with fundamental traffic parameters that enable the macroscopic behavior of the traffic network to be studied. With the assumptions on input traffic parameters such as a saturation flow rate of 1800 vehicles per hour, determination of 6 seconds time step, and road length divided into homogeneous cells of $85 \mathrm{~m}$ each, it is able to predict the lane that is becoming congested with an input traffic signal. It also provides an approximate prediction on the level of service at the signalized intersection. However, it is largely deterministic without stochastic variables such as driver's behavior in lane changing which affects lane utilization. It is also assumed that the cars start to move instantaneously when the green period starts, while in reality, drivers have different reaction times which also affects the accuracy of the model.

\section{CONCLUSIONS AND RECOMMENDATIONS FOR FUTURE WORK}

This paper has discussed the development of the Cell Transmission Model (CTM) in delay estimation by considering traffic signal optimization at an urban signalized intersection. The modeling approach is run based on several assumptions and input traffic parameters as determined and observed from field data collection. The results indicate that CTM is able to predict the phenomenon of queue formation and dissipation while providing an accurate prediction on the level of service of the signalized intersection. Traffic signal optimization that was applied in CTM yields a positive output in terms of reduced delay and rate of platoon formation and dispersion, but unable to improve the level of service in the case of worst lane experiencing a massive delay.

Shockwave speed variation is adopted in this model to capture the dynamic movement of vehicles. It aims to provide a more realistic simulation approach to delay estimation however it is yet to be validated for its accuracy in delay estimation. Hence future research could be done to investigate the performance of the shockwave speed variation in delay estimation.

\section{REFERENCES}

Akcelik, R. (1996). Signalized \& Unsignalized Intersection Design \& Research AID (SIDRA). Transport Research Ltd, Australia.

Akcelik, R. (2014). "A new lane-based model for platoon patterns at closely-spaced signalized intersections". in 26th ARRB Conference. Sydney, Australia.

Astarita, V. (2002). "Node and link models for network traffic flow simulation". Mathematical and Computer Modelling, Vol. 35, No. 5-6, pp. 643-56.

Balijepalli, N., Ngoduy, D. \& Watling, D. (2014). "The two-regime transmission model for network loading in dynamic traffic assignment problems". Transportmetrica $A$ : Transport Science, Vol. 10, No. 7, pp. 563-84.

Daganzo, C.F. (1994). "The cell transmission model: A dynamic representation of highway traffic consistent with the hydrodynamic theory". Transportation Research Part B: Methodological, Vol. 28, No. 4, pp. 269-87.

Drew, D.R. (1968). Traffic flow theory and control. McGraw-Hill. New York.

Girianna, M. \& Benekohal, R.F. (2004) "Using genetic algorithms to design signal coordination for oversaturated networks". Journal of Intelligent Transportation Systems, Vol. 8, No. 2, pp. 117-29.

Husch, D. \& Albeck, J. (2003). Synchro 6: Traffic signal software, user guide. Trafficware Limited. Albany, California. 
Knoop, V., van Zuylen, H. \& Hoogendoorn, S. (2008). "The influence of spillback modelling when assessing consequences of blockings in a road network". EJTIR, Vol. 4, No. 8, pp. 287-300.

Lighthill, M.J. \& Whitham, G.B. (1955). "On kinematic waves. II. A theory of traffic flow on long crowded roads". in Proceedings of the Royal Society of London A: Mathematical, Physical and Engineering Sciences, Vol. 229, pp. 317-45.

Lo, H.K. (1999). “A novel traffic signal control formulation". Transportation Research Part A: Policy and Practice, Vol. 33, No. 6, pp. 433-48.

Lo, H.K. (2001). "A cell-based traffic control formulation: strategies and benefits of dynamic timing plans". Transportation Science, Vol. 35, No. 2, pp. 148-64.

Mardiati, R., Ismail, N. \& Faroqi, A. (2014). "Review of Microscopic Model for Traffic Flow". ARPN Journal of Engineering and Applied Sciences, Vol. 9, No. 10.

Mathew, T.V. (2014). “Transportation Systems Engineering”. Cell Transmission Models. IIT Bombay.

Nyantakyi, E.K., Owusu, P.A. \& Borkloe, J.K. (2014). "Methods for the Assessment of Performance Indication Measures at Amakom Intersection and their Application in Micro Simulation Modeling". International Journal for Traffic and Transport Engineering, Vol. 4, No. 1, pp. 35-51.

Richards, P..I (1956). "Shock waves on the highway". Operations Research, Vol. 4, No. 1, pp. 42-51.

Smit, R. (2006). "An examination of congestion in road traffic emission models and their application to urban road networks". Phd Report.

Sunkari, S. (2004). "The benefits of retiming traffic signals". Institute of Transportation Engineers. ITE Journal, Vol. 74, No. 4, p. 26.

Suprayitno, H. \& Soemitro, R.A.A. (2018). "Preliminary Reflexion on Basic Principle of Infrastructure Asset Management". Jurnal Manajemen Aset Infrastruktur \& Fasilitas, Vol. 2, No. 1, Maret 2018, Hal. : 1-10.

Wallace, C.E., Courage, K., Reaves, D., Schoene, G. \& Euler, G. (1984). TRANSYT-7F user's manual.

Wang, J., Lu, H. \& Peng, H. (2008). “System Dynamics Model of Urban Transportation System and Its Application". Journal of Transportation Systems Engineering and Information Technology, Vol. 8, No. 3, pp. 83-9.

Wang, P. (2010). Conditional cell transmission model for two-way arterials in oversaturated conditions, Vol. 71.

Wang, P., Jones, L., Yang, Q. \& Gurupackiam, S. (2013). "Cell transmission model-based traffic signal timing in oversaturated conditions". Journal of Central South University, Vol. 20, No. 4, pp. 1129-36.

Wu, W., Shen, L., Jin, W. \& Liu, R. (2015). "Density-based mixed platoon dispersion modeling with truncated mixed Gaussian distribution of speed". Transportmetrica B: transport dynamics, Vol. 3, No. 2, pp. 114-30.

Zhu, F., Lo, H.K. \& Lin, H-Z. (2013). "Delay and emissions modeling for signalized intersections". Transportmetrica B: Transport Dynamics, Vol. 1, No. 2, pp. 111-35. 
(e)ISSN 2656-8896 (p)ISSN 2656-890X

Journal of Infrastructure and Facility Asset Management - Vol. 2, Issue. 1, March 2020 